\title{
STUDY OF THYROID PROFILE IN BETA THALASSEMIA MAJOR CHILDREN OF NORTH BIHAR AND ITS CORRELATION WITH SERUM FERRITIN LEVELS
}

\author{
Kripa Nath Mishra1, Anil Kumar²
}

1 Professor and HOD, Department of Paediatrics, Darbhanga Medical College and Hospital, Laheriasarai, Darbhanga, Bihar, India. 2Postgraduate Student, Department of Paediatrics, Darbhanga Medical College and Hospital, Laheriasarai, Darbhanga, Bihar, India.

ABSTRACT
BACKGROUND
Thalassemia major is an inherited disease, caused by abnormal hemoglobin synthesis that results from alteration in the rate of
globin chain production. Blood transfusion in beta-thalassemia patient is essential for prolonging life. There may be an overload of
iron with repeated blood transfusion and inadequate iron chelation therapy, which can lead to various endocrine complications
such as hypothyroidism, cardiomyopathy, growth hormone deficiency, diabetes mellitus, hypoparathyroidism and
hypogonadotropic gonadism. We wanted to study the incidence of Hypothyroidism in children with thalassemia major on regular
blood transfusion and its correlation with serum ferritin levels that indicate iron overload in thalassemia patients.

\section{METHODS}

50 children with beta-thalassemia major, who received regular blood transfusion therapy for at least two years and was selected with a ferritin level greater than $1000 \mu \mathrm{gm} / \mathrm{dl}$. Important history with clinical examination of each patient was recorded. Thyroid function tests and serum ferritin value were recorded from the patient's data and analysed.

\section{RESULTS}

$24 \%$ of patients were subclinical hypothyroidism and $2 \%$ had overt hypothyroidism. Incidence of hypothyroidism has no direct correlation with serum ferritin level in this study.

\section{CONCLUSIONS}

Hypothyroidism was seen in about $26 \%$ of children with thalassemia major in our study. Detecting hypothyroidism is important for patient because effective thyroid hormone replacement therapy is easy and possible. Therefore, thyroid function test should be monitored from time to time, especially when there are complications related to iron overload. With early identification and prevention of various endocrine complications it is possible to maintain the life of these children fairly comfortably and also increase the life expectancy.

\section{KEY WORDS}

Beta thalassemia, Hypothyroidism, Serum Ferritin, Hemosiderosis

HOW TO CITE THIS ARTICLE: Mishra KN, Kumar A. Study of thyroid profile in beta thalassemia major children of North Bihar and its correlation with serum ferritin levels. J. Evolution Med. Dent. Sci. 2019;8(24):1882-1885, DOI: 10.14260/jemds/2019/414

\section{BACKGROUND}

Thalassemia refers to a group of inherited disorders, inherited as an autosomal recessive disease, caused by a defect or reduction in globin chain production, resulting in a disproportion between the $\alpha$-globin and $\beta$-globin chain. There is $25 \%$ chance that children born in each pregnancy develop thalassemia major. More than 200-250 mutations have been observed in patients of thalassemia. In $\beta$ thalassemia major, there is decreased level of normal hemoglobin due to inadequate $\beta$-goblin gene production and excess unpaired $\alpha$-globin that forms $\alpha$-globin tetramers, appears as insoluble inclusions in red cell. In beta thalassemia, gamma chain synthesis persists after fetal life.

Hence, the $\mathrm{HbF}$ which has more affinity to oxygen is increased. Insoluble Inclusions are very unstable, interfere with cell division, damage red blood cell, perturb the internal

'Financial or Other Competing Interest': None.

Submission 25-02-2019, Peer Review 30-05-2019,

Acceptance 06-06-2019, Published 17-06-2019.

Corresponding Author:

Dr. Anil Kumar,

$R / N-U / 8, P G-2$, Boy Hostel, DMCH Campus,

Laheriasarai, Darbhanga-846003, Bihar, India.

E-mail:dr.anilk2@gmail.com

DOI: $10.14260 /$ jemds $/ 2019 / 414$

(c) (i) $\ominus$ ionic environment precipitate in red cell precursors (Premature destruction of RBCs), reduced RBC deformity and ineffective erythropoiesis that leads to progressive anaemia ${ }^{1}$. A patient with thalassemia produces abnormal hemoglobin that cannot transport enough oxygen to tissue. This results in tissue hypoxia. This produces symptoms ranging from fatigue to organ damage. Increasing number of beta thalassemia patients is due to lack of knowledge and lack of access to health services.

All over world, there are more than 250 million $(1.5 \%$ of world populations) carriers of beta-thalassemia gene, and in south East Asia, there are 40 million carrier of gene. All over the world about 100, 000 children are born each year with beta-thalassemia major. With the birth rate of 22.8 per 1,000 in India, it is estimated that there are about 9, $000-10,000$ cases being added every year. Beta thalassemia patients in our country at given time is around 65, $000-67,000$. Thalassemia incidence varies in various communities, regions, and ethnic groups in India. Carrier rate of beta thalassemia gene in South India varies 1 to $3 \%$ and in North India it is $3 \%$ to $17 \%$ and $3 \%$ of world population carries alleles for $\beta$-thalassemia. This syndrome was earlier considered dead before the second decade of life. ${ }^{2}$ The combined effect of regular blood transfusion therapy and iron chelation therapy has increased the life expectation of $\beta$ thalassemia major patients, reduces various complications of 
thalassemia and improves quality of life of patients. Hematopoietic Stem cell transplantation (HSCT) is the only known curative treatment for thalassemia, which is costly and not affordable for each patient in countries like India. ${ }^{3}$ Poor outcome of HSCT occurs in patients with hepatomegaly, portal fibrosis and inadequate chelation prior to transplant. Prenatal diagnosis is done by foetal DNA analysis by blood sampling around 16-18 weeks of intrauterine life. As it is autosomal recessive disorder, genetic counselling is always helpful for prevention of disease.

Thalassemia major is also known as Cooley's anaemia. Severe beta thalassemia is characterized by transfusion dependent anaemia, usually manifest in the first year of life (6-18 Month) when HbF declines normally. They manifest as gradually increasing pallor, poor feeding, failure to thrive, irritability, fatigability, intermittent infections (Fever and diarrhoea), jaundice and develop hepatosplenomegaly. Affected children grow well for initial few months of life after birth. No anaemia is observed during newborn period. In India, many children born with thalassemia major die undiagnosed, due to the lack of investigation facilities and treatment. If undiagnosed and untreated, more than $90 \%$ do not survive beyond 3-4 years of age without transfusion. The spectrum of clinical manifestation of beta thalassemia varies widely. Tissue hypoxia stimulate production of more erythropoietin. This results in increased medullary and extramedullary erythropoiesis. Untreated or irregularly treated children develop significant hemolytic (Chipmunk) facies due to extramedullary erythropoiesis results in expansion of bone marrow space, including fronto-parietal and occipital bossing with a hot cross bun appearance of skull (Caput quadratum), hair on end appearance of skull results from widening of the diploic spaces, depressed bridge of nose, malar prominence, and malocclusion of teeth with protrusion of maxillary teeth, distortion and osteoporosis of ribs and vertebrae, pathological fracture of long bones, splenomegaly with its complications hypersplenism, hepatomegaly, gallstone and chronic leg ulcers. Ineffective erythropoiesis creates a hypermetabolic state associated with fever and failure to thrive. Hyperuricemia may be present.

Blood smear shows hypochromia, microcytosis, marked anisocytosis, fragmented and nucleated red cells, polychromasia and occasionally immature leukocytes. Organomegaly is reduced in well transfused patients, but is marked in patients receiving irregular or inadequate transfusion support.

Physiologically, there is no such mechanism in our body to eliminate extra body iron due to regular blood transfusion and therefore increasing absorption of intestinal iron, the iron overload will ultimately become. ${ }^{4}$ Iron overload is a major cause of morbidity. Transfusion induced hemosiderosis becomes the major clinical complication of transfusion dependent thalassemia. Each $\mathrm{ml}$ of packed red cells contains $1 \mathrm{mg}$ of iron. Iron is primarily deposited in liver and liver hemosiderosis develops after one year of chronic blood transfusion therapy and also leads to iron deposition in various endocrine glands of body. This lead to a higher incidence of endocrine complications such as hypothyroidism, hypogonadotropic gonadism (Delayed puberty), hypoparathyroidism, growth hormone deficiency and pancreatic dysfunction. ${ }^{5}$ After 10 year of blood transfusion therapy, diabetes mellitus, cardiac complications
(Congestive failure, arrhythmia) secondary to hemosiderosis develops; therefore most patients not receiving satisfactory iron chelation therapy die from cardiac complications such as cardiac failure and cardiac arrhythmia secondary to hemosiderosis. Hence, adequate iron chelation therapy reduces hemosiderosis induced morbidity. The overload of iron in the body can be predicted by serum ferritin, serum iron and total iron binding capacity (TIBC) levels. Other investigation includes liver biopsy, liver MRI, and echocardiography. An accurate and noninvasive tool to asses cardiac iron status is cardiac magnetic resonance (CMR). Estimating serum ferritin levels is the most frequently used test for predicting the burden of iron in $\beta$-thalassemia major patients. The relationship between serum ferritin and iron levels in the body is well recognized and the test is easier to do and compared to another test for iron overload. ${ }^{6}$ Thyroid disturbance is observed to be common in Thalassemia major, but its frequency and severity varies in different cohort, and the exact description of long-standing natural history has been partly described. Primary hypothyroidism is the most frequent type of thyroid disease observed in thalassemia. However, frequency of hypothyroidism shows the difference depending on the area, treatment quality and treatment protocol. Thyroid dysfunction usually occurs in thalassemic patients at the frequency of 13 to $60 \%$, after 10 years, which is mainly in the form of subclinical hypothyroidism. ${ }^{7}$

Transfusion should generally be given at interval of 3-4 weeks, with the goal being to maintain a pretransfusion hemoglobin level of 9.5-10.5 gm/dl. The introduction of chelating agents capable of removing excess iron from the body has dramatically increased life expectancy. Combination therapy may be needed in children not adequately controlled by appropriate use on a single iron chelator. Most widely used iron chelator is desferrioxamine. Iron chelation therapy should start as soon as the patient becomes significantly overloaded and/or serum ferritin greater than $1,000 \mathrm{ng} / \mathrm{ml}$ In India, the expenditure of iron chelation therapy for most patients leaves ideal treatment, and compliance of the blood transfusion is often poor. Hence, it is possible that children with thalassemia have high prevalence of hypothyroidism. Thyroid profile was evaluated in children of thalassemia major and the outcome were correlated with serum ferritin levels.

\section{METHODS}

This cross-sectional study was done on 50 children of beta thalassemia major, who received regular blood transfusion therapy for at least two years and were selected with a ferritin level is greater than $1000 \mu \mathrm{gm} / \mathrm{dl}$. Consent has been taken from parents of all children. Detailed history and clinical examination were recorded in the Department of Pediatrics, Darbhanga Medical College and Hospital, Laheriasarai, Bihar. The blood sample was collected for estimation of thyroid profile and serum ferritin value noted from the patient record and this data was used for analysis. Sample size was taken for convenience.

Study by purposive sampling technique, since the duration of study was less. The patients were selected by purposive sampling technique. Selection within the strata is done for convenience. For this study, Ethical committee clearance has been obtained from DMCH ethical committee. 


\begin{tabular}{|c|c|c|c|c|c|c|}
\hline \multirow{3}{*}{$\begin{array}{c}\text { Age } \\
\text { (Years) }\end{array}$} & \multicolumn{6}{|c|}{ Thyroid Function Groups } \\
\hline & \multicolumn{2}{|c|}{ Euthyroid (A) } & \multicolumn{2}{|c|}{$\begin{array}{c}\text { Subclinical } \\
\text { Hypothyroidism } \\
\text { (B) }\end{array}$} & \multicolumn{2}{|c|}{$\begin{array}{c}\text { Overt } \\
\text { Hypothyroidism } \\
\text { (C) }\end{array}$} \\
\hline & $\begin{array}{c}\text { No. of } \\
\text { Patients }\end{array}$ & $\%$ & $\begin{array}{c}\text { No. of } \\
\text { Patients }\end{array}$ & $\%$ & $\begin{array}{c}\text { No. of } \\
\text { Patients }\end{array}$ & $\%$ \\
\hline $3-4$ & 8 & 21.62 & 0 & 0 & 0 & 0 \\
\hline $4-6$ & 10 & 27.03 & 2 & $\mid 16.67$ & 0 & 0 \\
\hline $6-8$ & 6 & 16.22 & 2 & 16.67 & 0 & 0 \\
\hline $8-10$ & 8 & 21.62 & 5 & \begin{tabular}{|l|}
41.66 \\
\end{tabular} & 0 & 0 \\
\hline $10-12$ & 5 & 13.51 & 3 & 25 & 1 & 100 \\
\hline Total & 37 & 100 & 12 & 100 & 1 & 100 \\
\hline$T$ Tabl & Thyr & unct & $\begin{array}{l}\text { n Differe } \\
\text { ulations }\end{array}$ & t Age & oups c & \\
\hline
\end{tabular}

\begin{tabular}{|c|c|c|c|}
\hline $\begin{array}{c}\text { Thyroid Function } \\
\text { Group }\end{array}$ & T3 (ng/d) & T4 ( $\mu \mathrm{g} / \mathbf{d l})$ & TSH (mIU/l) \\
\hline Euthyroid (A) & $138.90 \pm 22.51$ & $7.77 \pm 1.95$ & $3.02 \pm 1.27$ \\
\hline Subclinical (B) & $135.04 \pm 23.13$ & $7.10 \pm 1.60$ & $9.25 \pm 2.49$ \\
\hline $\begin{array}{c}\text { Overt } \\
\text { hypothyroidism(C) }\end{array}$ & $86.5 \pm 4.5$ & $1.40 \pm 0.37$ & $58.86 \pm 8.86$ \\
\hline Table 2. Mean Values of T3, T4 and TSH in different Thyroid \\
Function Groups \\
\hline
\end{tabular}

\begin{tabular}{|c|c|c|c|}
\hline $\begin{array}{c}\text { Thyroid Function } \\
\text { Groups }\end{array}$ & Mean T3 & Mean T4 & Mean TSH \\
\hline Group A vs. B & 0.274 & 0.054 & $0.001^{*}$ \\
\hline Group A vs. C & $0.004^{*}$ & $0.041^{*}$ & $0.001^{*}$ \\
\hline Group B vs. C & $0.001^{*}$ & $0.005^{*}$ & $0.001^{*}$ \\
\hline \multicolumn{3}{|c|}{ Table 3. Comparison of Thyroid Functions (T3, T4, TSH) in } \\
Different Thyroid Groups \\
\hline \multicolumn{4}{|c|}{${ }^{*}$ p-value significant } \\
\hline
\end{tabular}

\begin{tabular}{|c|c|c|c|c|c|c|}
\hline $\begin{array}{c}\text { Serum } \\
\text { Ferritin } \\
(\boldsymbol{\mu g} / \mathbf{d l})\end{array}$ & Euthyroid & $\%$ & $\begin{array}{c}\text { Subclinical } \\
\text { Hypothyroid }\end{array}$ & $\%$ & $\begin{array}{c}\text { Overt } \\
\text { Hypothyroid }\end{array}$ & $\%$ \\
\hline$<2000$ & 15 & 40.54 & 4 & 33.33 & 0 & 0 \\
\hline $2001-3000$ & 10 & 27.03 & 2 & 16.67 & 1 & 100 \\
\hline $3001-4000$ & 9 & 24.32 & 3 & 25 & 0 & 0 \\
\hline$>4000$ & 3 & 8.11 & 3 & 25 & 0 & 0 \\
\hline Total & 37 & 100 & 12 & 100 & 1 & 100 \\
\hline
\end{tabular}

\begin{tabular}{|c|c|c|c|}
\hline Group & $\begin{array}{c}\text { Serum Ferritin } \\
\text { Mean } \pm \text { SD }\end{array}$ & \multicolumn{2}{|c|}{ p-Value } \\
\hline Group A (Euthyroid) & $2384.21 \pm 1893.73$ & $\begin{array}{c}\text { Group A } \\
\text { vs. B }\end{array}$ & 0.102 NS \\
\hline Group B (Subclinical) & $3064.69 \pm 1193.31$ & $\begin{array}{c}\text { Group B } \\
\text { vs. C }\end{array}$ & 0.407 NS \\
\hline $\begin{array}{c}\text { Group C (Overt } \\
\text { hypothyroidism) }\end{array}$ & $2218.53 \pm 337.49$ & $\begin{array}{c}\text { Group A } \\
\text { vs. C }\end{array}$ & 0.902 NS \\
\hline Table 5. Comparison of Mean Serum Ferritin Levels Between \\
Different Thyroid Groups \\
\hline \multicolumn{4}{|c|}{ NS- Not Significant } \\
\hline
\end{tabular}

\section{Statistical Analysis}

The software used in this study for statistical analysis is 22.0 and data was analysed using One-way ANOVA test \& fisher's exact between the groups and $\mathrm{P}<0.001$ was considered significant.

\section{RESULTS}

Group A: Euthyroid. Group B: Subclinical hypothyroidism. Group C: Overt hypothyroidism.
Of total 50 children included for this study, $60 \%$ were males and $40 \%$ were females. Hypothyroidism was established in $26 \%$ of beta thalassemia patients, with $24 \%$ subclinical hypothyroidism and $2 \%$ overt hypothyroidism in this study. Below in Table 1, out of 12 subclinical hypothyroid thalassemia patients $16.7 \%, 16.7 \%, 41.66 \%$ and $25 \%$ were of 4-6 years, 6-8 years, 8-10 years and $10-12$ years respectively. In 3 to 4 years old group none of the patients were subclinical hypothyroidism. In this study hypothyroidisms group 1 $(100 \%)$ was in the 10 to 12 age group. The mean T3 and T4 were lower in the overt Hypothyroidism group and normal in subclinical hypothyroidism groups. Mean TSH level was elevated in both subclinical and overt hypothyroidism group (Table 2). In the statistical analysis, there was major difference between the mean T3, T4 and TSH level of euthyroid and hypothyroid groups (Table 3).

\section{DISCUSSION}

The current study was done to determine serum concentrations of ferritin, T3, T4 and TSH in beta-thalassemic major patients on regular blood transfusion and correlation of thyroid function with relation to serum ferritin level. In this study, $74 \%$ of patients had normal thyroid function and $26 \%$ had abnormal thyroid function. In thyroid dysfunction, raised TSH level was observed in $24 \%$ of Thalassemia patients, which was reliable with diagnosis of subclinical hypothyroidism. Likewise, raised TSH level was the most frequent thyroid dysfunction in prior studies of Pirinccioglu et $\mathrm{al}^{7}{ }^{7}$ Jaruratanasirikul et $\mathrm{al}^{8}{ }^{8}$ Malik et $\mathrm{al}^{9}{ }^{9}$ Hashemizadeh et $\mathrm{al}^{10}$ and Gathwala et al. ${ }^{11}$ In this study, $2 \%$ of patients had lower T4 and higher TSH, reliable with the diagnosis of overt hypothyroidism. Once again, present study is equivalent to the study done by Solanki et al.12 Similarly many workers, such as Malik et $\mathrm{al}^{9}(1.4 \%)$, Hashemizadeh et al ${ }^{10}(1 \%)$, a small number of patients were also found overt hypothyroidism. This observation of thyroid dysfunction in the current study was not equivalent with the conclusion of Costin et $\mathrm{al}^{13}$ and Kuo et $\mathrm{al}^{14}$ because they found normal thyroid function in Thalassemia patients. No clinical hypothyroidism was found in this study, but it was reported $6.9 \%$ for Agarwal et al, $154 \%$ by Zervas et al. 16 and $18.3 \%$ for Magro et al. ${ }^{17}$ In the current study, the mean value of T3 and T4 and TSH in euthyroid were $138.90 \pm 22.51,7.77 \pm 1.95$, $3.02 \pm 1.27$ respectively, $135.04 \pm 23.13,7.10 \pm 1.60,9.25 \pm$ 2.49 respectively in subclinical hypothyroid group and $86.5 \pm$ $4.5,1.40 \pm 0.37,58.86 \pm 8.86$, respectively, reported in the group of overt hypothyroidism. In present study, there are significant differences between the mean values of thyroid hormones in euthyroid and hypothyroid groups (Table 3). Results of this study were similar to a study of Agarwal et al 15 , in which there was considerable difference in thyroid function tests (T3, T4 and TSH) between euthyroid and hypothyroid groups.

Even though serum ferritin level is the most commonly used test for assessing the status of iron in these patients, but the current study shows a statistically insignificant difference in the mean level of serum ferritin between hypothyroid and euthyroid groups (Table 5). Similar observations have been repeated in prior studies by Shamshirsazet et al, ${ }^{3}$ Agarwal et $\mathrm{al}^{15}$ Jarurtanasirikul et $\mathrm{al}^{8}$ and Zervas et al. This study suggests that single serum ferritin alone is not enough to decide chronic risk of iron overload in the development of 
thyroid dysfunction. There is no uncertainty that overloading of iron in thyroid and other endocrine dysfunction plays an important role in Thalassemia patients. In our studies, a negligible difference between the serum ferritin levels of hypothyroid and euthyroid groups, and the above-mentioned studies,3,8,15,18 shows that the damage of various endocrine glands caused by chronic hypoxia due to prolonged anaemia may be an associated cause responsible for thyroid dysfunction. The opposite results of thyroid current studies were shown by Pirinccioglu et $\mathrm{al}^{7}$ which showed a much higher serum ferritin level in the hypothyroid group compared to the euthyroid group.

\section{CONCLUSIONS}

Hypothyroidism is an important complication in approximately $26 \%$ of children with beta thalassemia major; although $24 \%$ of children with thalassemia major have subclinical hypothyroidism and only $2 \%$ have overt hypothyroidism. In addition, serum ferritin level does not have any direct correlation with thyroid dysfunction in these thalassemia patients. Most of the patients of hypothyroidism were subclinical; their regular clinical examination for detection of any complication of overt hypothyroidism, along with their periodic evaluation of the thyroid function was done to detect children of hypothyroidism who need thyroid replacement therapy. This is essential because early detection and management of overt hypothyroidism will definitely lead to better quality of life and reduces the complications of thalassemia in these patients, especially in relation to development and growth. Early replacement therapy increases life expectancy of patients. In addition, lifetime thyroid hormone replacement therapy for hypothyroid is relatively inexpensive and easy to administer.

\section{REFERENCES}

[1] Galanello R, Origa R. Beta thalassemia. Orphanrt J Rare Dis 2010;5:11.

[2] Lokeshwar MR. Progress in the management of thalassemia. Indian Pediatr 2006;43:503-6.

[3] Shamshirsaz AA, Bekheirnia MR, Kamgar M, et al. Metabolic and endocrinologic complications in $\beta$ thalassemia major. BMC Endocrine Disorders 2003;3(1):4.

[4] Cunningham MJ, Macklin EA, Neufeld EJ, et al. Complications of $\beta$-thalassemia major in North America. Blood 2004;104(1):34-9.

[5] Gulati R, Bhatia V, Agarwal SS. Early onset of endocrine abnormalities in $\beta$-thalassemia major in a developing country. J Pedi Endocrinol Metab 2000;13(6):651-6.
[6] Ikram N, Hassan K, Younas M, et al. Ferritin levels in patients of $\beta$-thalassemia major. Int $\mathrm{J}$ Pathology 2004;2(2):71-4.

[7] Pirinççioğlu AG, Deniz T, Gökalp D, et al. Assessment of thyroid function in children aged 1-13 years with betathalassemia major. Iran J Pediatr 2011;21(1):77-82.

[8] Jaruratanasirikul S, Wongcharnchailert M, Laosombat $\mathrm{V}$, et al. Thyroid function in beta-thalassemic children receiving hypertransfusions with suboptimal ironchelating therapy. J Med Assoc Thai 2007;90(9):1798802.

[9] Malik SA, Syed S, Ahmed N. Frequency of hypothyroidism in patients of beta-thalassaemia. J Pak Med Assoc 2010;60(1):17-20.

[10] Hashemizadeh $H$, Noori R. Assessment of hypothyroidism in children with $\beta$-thalassemia major in North Eastern Iran. Iran J Pediatr Hematol Oncol 2012;2(3):123-7.

[11] Gathwala G, Das K, Agrawal N. Thyroid hormone profile in Beta thalassemia major children. Indian J Pediatr 2009;4(2):20-9.

[12] Solanki US, Bhargava AK, Adole PS. Assessment of thyroid function in multi-transfused children of $\beta$ thalassemia major with iron overload. World J Pharmacy Pharmaceutical Sciences 2014;3(8):217783.

[13] Costin G, Kogut M, Hyman CB, et al. Endocrine abnormalities in Thalassaemia major. American Journal of Diseases in Children 1979;133(5):497-502.

[14] Kuo B, Zaino E, Roginsky MS. Endocrine function in Thalassemia major. Journal of Clinical Endocrinology and Metabolism 1968;28(6):805-8.

[15] Agarwal MB, Shah S, Vishwanathan C, et al. Thyroid dysfunction in multi-transfused iron loaded Thalassemia patients. Indian Pediatr 1992;29(8):997102.

[16] Zervas A, Katopodi A, Protonotariou A, et al. Assessment of thyroid function in two hundred patients with $\beta$-Thalassemia major. Thyroid 2002;12(2):151-4.

[17] Magro S, Puzzonia P, Consarino $C$, et al. Hypothyroidism in patients with thalassemia syndromes. Acta Haematol 1990;84(2):72-6.

[18] Jaipuria R, Nigam RK, Malik R, et al. Assessment of thyroid function in children with Beta-Thalassemia major and its correlation with serum ferritin and transfusion index. J of Evolution of Medical \& Dental Sciences 2014;3(4):847-54. 